Universidade Federal do Rio Grande do Sul, Instituto de Geociências, Programa de Pós-Graduação em Geografia, Porto

Alegre, RS, Brasil

\title{
Dinâmica espaço-temporal das macrófitas aquáticas no Banhado Grande, bacia hi- drográfica do Rio Gravataí, RS
}

\author{
Marcelo Guglielmi Leite ${ }^{1}$, Laurindo Antonio Guasselli²
}

\begin{abstract}
${ }^{1}$ Universidade Federal do Rio Grande do Sul - Departamento de Humanidades - Colégio de Aplicação. Avenida Bento Gonçalves, 9500, Agronomia, Porto Alegre, RS, Brasil. Email: marcelo_geoufrgs@yahoo.com.br

${ }^{2}$ Universidade Federal do Rio Grande do Sul - Departamento de Geografia - Programa de Pós-Graduação em Geografia. Avenida Bento Gonçalves, 9500, Agronomia, Porto Alegre, RS, Brasil. Email: laurindo.guasselli@ufrgs.br
\end{abstract}

Recebido em 04/2013. Aceito para publicação em 10/2013.

Versão online publicada em 08/11/2013 (http://seer.ufrgs.br/paraonde)

\begin{abstract}
Resumo - Os banhados constituem uma entre as diversas tipificações das terras úmidas. Sua importância vincula-se à função de controle de vazão das águas superficiais dos corpos hídricos aos quais estão associados e também como habitat de distintas espécies. 0 entendimento da dinâmica de banhados sugere uma abordagem espaço-temporal, a fim de se mensurar e qualificar os elementos fundamentais da paisagem e compreender o seu funcionamento. Este estudo investiga a dinâmica temporal dos padrões de distribuição espacial das macrófitas aquáticas do Banhado Grande, bacia do rio Gravataí, com a utilização de técnicas de sensoriamento remoto e geoprocessamento. Foram gerados mapas referentes aos diferentes padrões de distribuição espaço-temporal da vegetação, a partir de imagens orbitais LANDSAT-TM, no período entre 1994 e 2010, agrupadas por estações do ano. As variações espaço-temporais observadas nesse estudo estão associadas à variabilidade hidrodinâmica do sistema, entretanto, esse padrão é apenas parcialmente sazonal.

Palavras-chave: Banhado Grande. Bacia hidrográfica do rio Gravataí. Dinâmica espaço-temporal. Macrófitas aquáticas. Sensoriamento remoto.
\end{abstract}

\section{INTRODUÇÃO}

O termo banhado é uma denominação própria do Rio Grande do Sul e provém do termo espanhol "bañado", devido à influência dos países que fazem fronteira com o estado e é utilizado como sinônimo de outros termos como brejos ou charcos (INSTITUTO BRASILEIRO DO MEIO AMBIENTE E RECURSOS NATURAIS RENOVÁVEIS, 2000). Conforme Carvalho \& Ozório (2007), banhados são definidos como terras permanentemente ou temporariamente alagadas, marcados pela abundante vegetação submersa, emersa ou flutuante e sem uma bacia de acumulação de água bem definida. Os banhados realizam importante função de regulação do escoamento das águas superficiais e subterrâneas dos corpos hídricos aos quais estão conectados, além de servirem como abrigo ou importantes habitats de inúmeras espécies de animais (IBAMA, 2000).

A água que encharca essas terras provém de corpos hídricos próximos ou adjacentes ao sistema, como rios, lagoas, lagunas ou aporte de água subterrânea, promovido pelo transbordamento do lençol freático (IBAMA, 2000). Isso pode estar associado à ocorrência dos "pulsos" de inundação, decorrentes do período das estações chuvosas na região (NEIFF, IRIONDO \& CARIGNAN, 1994). Os pulsos de inundação participam ativamente da dinâmica espaço-temporal do elemento da paisagem que melhor delimita visualmente os banhados: a vegetação paludosa, ou vegetação de macrófitas aquáticas (RINGUELET, 1962; FRANTZ et al., 1990). Ge- nericamente, as macrófitas aquáticas são plantas cujas partes fotossintetizantes estão permanentemente ou parcialmente submersas ou em flutuação (IRGANG \& GASTAL JR., 1996). Guasselli (2005) analisa a variação do padrão do nível de água como principal fator que afeta a distribuição espacial de macrófitas aquáticas em terras úmidas e a sua relação com o padrão hidrodinâmico.

O Banhado Grande, conjuntamente com o Banhado dos Pachecos, forma uma extensa composição de áreas úmidas na bacia hidrográfica do rio Gravataí (Figura 1), definida por Meneghetti (1998) como "Sistema Banhado Grande" (SBG). Dos 450 km2 do SBG, há $138 \mathrm{~km} 2$ que estão permanentemente alagados, sendo cerca de $50 \mathrm{~km} 2$ do total pertencente à área do Banhado Grande (MELLO, 1998). A bacia do Gravataí situa-se na região nordeste do estado do Rio Grande do Sul e ocupa uma área de aproximadamente $2020 \mathrm{~km} 2$ (MELLO, 1990).

O Sistema Banhado Grande pode ser classificado, segundo Ramsar (1999), como um ambiente de "turfeiras não florestadas" cercadas por "terra irrigada". A formação do SBG remonta aos principais episódios transgressivos-regressivos ocorridos na área no período quaternário (TOMAZELLI \& VILLWOCK, 2000).

De modo geral, os estudos sobre a bacia e sobre o banhado (FUNDAÇÃO ZÔOBOTÂNICA DO RIO GRANDE DO SUL, 1983; DEPARTAMENTO NACIONAL DE OBRAS E SANEAMENTO, 1985; ECOPLAN ENGENHARIA \& COMPANHIA RIO-GRANDENSE DE SANEMANTO, 1992; 


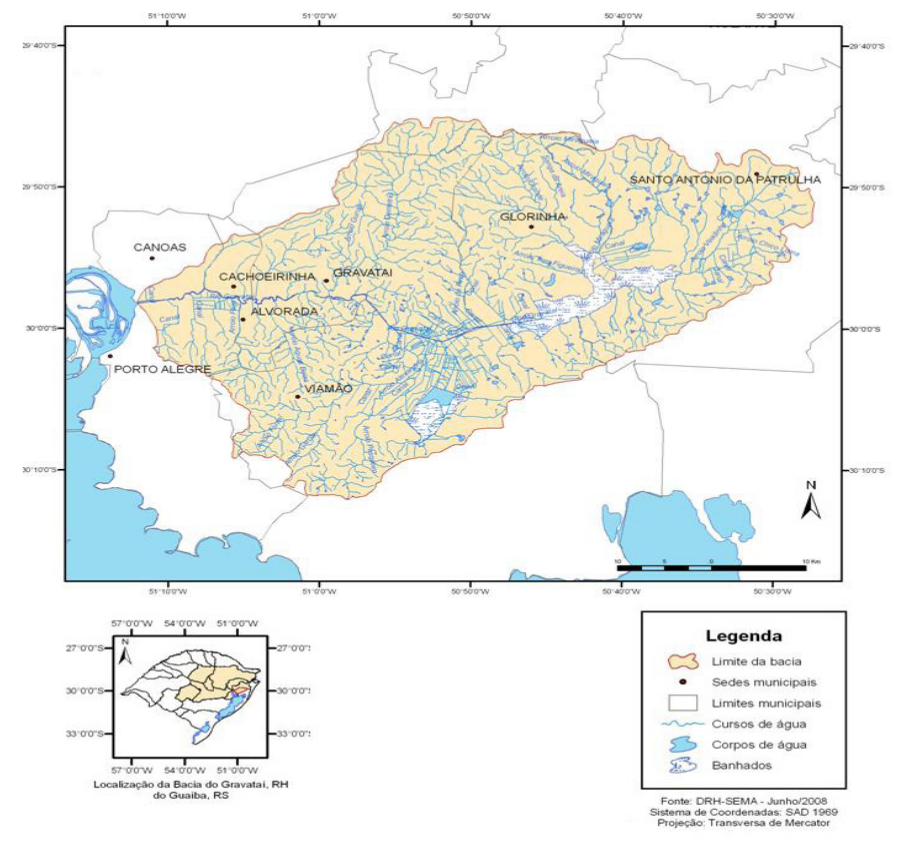

Figura 1. Mapa da bacia hidrográfica do rio Gravataí, RS.

Fonte: Modificado de Secretaria Estadual do Meio Ambiente, RS (2008).

BULHÕES \& GIUGNO, 1994; UNIVERSIDADE FEDERAL DO RIO GRANDE DO SUL, 2002) tratam da identificação das espécies vegetais que compõem essas áreas úmidas de forma pontual. Poucos levam em consideração os condicionantes da distribuição espacial da vegetação componente dos banhados. Essa abordagem traz um entendimento restrito da dinâmica espaço-temporal de áreas úmidas.

A compreensão da dinâmica da vegetação paludosa no Banhado Grande, a partir dos padrões de distribuição espaço-temporal das macrófitas aquáticas, está relacionada ao fato de que essas são as plantas características dos banhados, CARVALHO \& OZORIO (2007). Essas plantas possuem adaptação aos ambientes alagadiços, sendo que suas regiões fotossintetizantes permanecem, permanente ou parcialmente, por grande por do ano, submersas.

A interação do ambiente aquático com a realização da fotossíntese pelas macrófitas aquáticas não as difere no seu processo de produção e crescimento (BIUDES \& CAMARGO, 2008) com relação às plantas terrestres, mas pode afetar, também, a resposta espectral em imagens orbitais, conforme análise de Frantz et al. (1990). No Banhado Grande, o padrão heterogêneo de distribuição das macrófitas, influenciado pela dinâmica de inundações e pela hidrodinâmica, acaba por formar uma estrutura em "mosaicos". Segundo Mello (1998), os mosaicos do Banhado Grande são perceptíveis pelo conjunto indissociável das características hidrodinâmicas e a conseqüente distribuição espacial da vegetação.

Assim o presente estudo analisa a dinâmica espaço-temporal das macrófitas aquáticas do Banhado Grande, na bacia hidrográfica do rio Gravataí, a partir de sensoriamento remoto e técnicas de geoprocessa- mento, utilizando imagens representativas de estiagem e de cheias, para identificar a ocorrência de padrões de cobertura vegetal.

\section{MATERIAIS E MÉTODOS}

Para atingir os objetivos propostos, as etapas realizadas foram as seguintes:

1a) Levantamento de dados sobre a bacia do rio Gravataí e o Banhado Grande: foram analisados estudos que abordassem informações físicas e geográficas como a hidrodinâmica na bacia e no Banhado, os contextos geológico-geomorfológico e climático e a cobertura vegetal, buscando compreender a complexidade ambiental do sistema Banhado Grande.

Foram organizadas séries históricas de precipitação, com dados coletados a partir de estações meteorológicas existentes na bacia e no perímetro adjacente, além de dados de pluviômetros localizados nos 09 (nove) municípios, LEITE (2011);

$2^{a}$ ) Levantamento de bases cartográficas: foi utilizado o Mapa Geológico de Rodrigues et al. (2000a, 2000b), elaborado pelo Centro de Pesquisas em Geologia Costeira e Oceânica da Universidade Federal do Rio Grande do Sul (CECO/UFRGS); as cartas topográficas da Diretoria do Serviço Geográfico do Exército (DSG); e dados do projeto de Drenagem do Banhado Chico Lomã, DNOS (1985);

$3^{\text {a }) ~ L e v a n t a m e n t o ~ d e ~ i m a g e n s ~ o r b i t a i s: ~ f o r a m ~ o b-~}$ tidas e processadas digitalmente imagens de satélite LANDSAT TM-5, organizadas de forma sazonal, Quadro 1.

Quadro 1. Organização sazonal das imagens orbitais Landsat TM

\begin{tabular}{|l|c|c|}
\hline Estações do ano & Data de imagem & Órbita/ponto \\
\hline VERÃO & $30 / 01 / 1994$ & $220 / 81$ \\
\hline OUTONO & $16 / 04 / 2010$ & $220 / 81$ \\
\hline INVERNO & $12 / 07 / 2001$ & $220 / 81$ \\
\hline PRIMAVERA & $01 / 10 / 2007$ & $220 / 81$ \\
\hline
\end{tabular}

4모 Expedições de campo: Para a caracterização da cobertura vegetal do Banhado Grande e do seu entorno adjacente, foram realizados 05 (cinco) trabalhos de campo, para registro fotográfico e análise da ocorrência de espécies dominantes de macrófitas aquáticas. Foram obtidas coordenadas a partir de Sistema de Posicionamento Global (GPS). Esses levantamentos auxiliaram na setorização do Banhado de acordo com os padrões de dominância das macrófitas aquáticas.

\section{Processamento das imagens orbitais}

Foram realizadas 03 (três) etapas de processamento para todas as imagens:

1) Georreferenciamento das imagens:

Para georreferenciamento das imagens foram utilizados pontos de controle, selecionados a partir de 
uma imagem Ikonos, no Google Earth. Uma data inicial foi georreferenciada, e as outras imagens foram registradas com base na primeira imagem georreferenciada.

$2^{\text {a }}$ ) Correção atmosférica da série temporal de imagens:

A correção atmosférica foi executada no software ENVI 4.3. 0 método é utilizado para atenuar os efeitos atmosféricos existentes na data de aquisição das imagens. Os dados de entrada para a correção levam em conta a data de passagem do satélite e elevação solar, ângulo de visada do satélite, contador digital e o máximo pixel escuro (dark pixel), contidos em cada data de imagem. 0 produto é uma imagem de reflectância média, expressa em valores entre 0 e 1 . Posteriormente as imagens foram convertidas para valores de contador digital entre 0 e 255 níveis de cinza.

$3^{a}$ ) Geração de polígonos limite do banhado sob 02 (duas) perspectivas:

(1 ${ }^{a}$ ) Geração de polígonos dos padrões, de cobertura de macrófitas aquáticas, nas 4 (quatro) imagens de satélite LANDSAT TM5, em cada estação do ano; (2 ${ }^{a}$ ) Quantificação da área dos polígonos a partir da ferramenta XTools do software ARCGIS.

\section{RESULTADOS E DISCUSSÕES}

As macrófitas aquáticas, principalmente aquelas flutuantes e de pequeno porte, estão sujeitas à movimentação da lâmina d'água (ARBO et al., 2001). Desta forma, é possível setorizar os padrões da dinâmica de macrófitas aquáticas do Banhado Grande e também os mosaicos de vegetação (MELLO, 1998). Para tanto, os mapas referentes aos padrões de distribuição espaço-temporal no período entre 1994 e 2010 foram agrupados por estações do ano. 0 mapeamento também permitiu a setorização de cada padrão segundo a observação da hidrodinâmica ocasionada por variações do componente precipitação (UFRGS, 2002; RUBBO, 2004) e retirada de água para a rizicultura (DNOS, 1985; MELLO, 1990).

A partir da resposta espectral e dos padrões espaço-temporal da vegetação paludosa em cada imagem, pode-se observar variações na dinâmica dos pulsos de inundação no Banhado Grande.

A Figura 2 apresenta as imagens do Banhado. $\mathrm{Na}$ imagem de verão, 30/01/1994 (Figura 2a), constata-se a inexistência de lâmina de água aparente. Essa característica indica um aspecto aparente de estiagem, que denota possivelmente, um nível de água real mais baixo no período de verão.

Contudo, esse padrão pode estar associado a uma maior produção primária (GUASSELLI, 2005; BIUDES \& CAMARGO, 2008), possibilitando uma cobertura mais homogênea formada pelas macrófitas aquáticas. Mas também pode estar associado a retirada de água no Banhado neste mesmo período para irrigação do arroz. Como o região central do Banhado é praticamente inacessível devido a grande presença de macrófitas
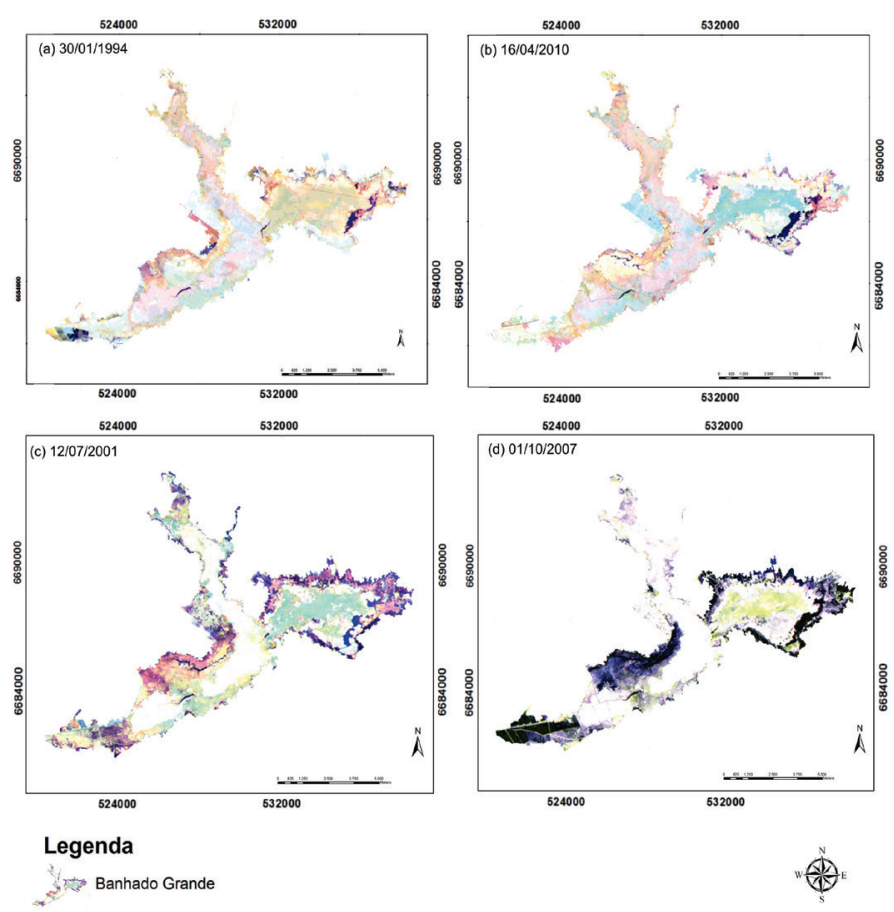

Y2to Banhado Grande

Figura 2. Imagens orbitais LANDSAT-TM5 do Banhado Grande. Composição colorida nas bandas 4, 5 e 3 .

aquáticas de grande porte, que funcionam literalmente como obstáculos de passagem, torna-se difícil um monitoramento com medidas de campo.

A classe com a maior abrangência espacial na imagem de verão de 30/01/1994 (Figura 3a) é a classe com predominância de gêneros de macrófitas do tipo "ciperáceas". Essas áreas constituem, de acordo com Irgang (1982), o "banhado grosso" ou "banhado alto" conforme Ecoplan Engenharia \& CORSAN (1992). Nessas áreas predominam as espécies de grande e médio porte, fixadas ao solo ou fixadas aos chamados "solos flutuantes" (NEIFF, 1997; ARBO et al., 2001; GUASSELLI, 2005), na denominação local "murchões".

Conforme Arbo et al. (2001), os solos flutuantes podem se mover, embora lentamente, conforme o comportamento da hidrodinâmica das áreas úmidas. Desse modo, as flutuações nos níveis de água e as percepções sobre inundações ou secas aparentes podem influenciar não só na hidrodinâmica, mas na quantidade de água nos solos flutuantes. A dinâmica associada a estes solos pode, eventualmente, provocar mudanças nas respostas espectrais da vegetação (FRANTZ et al., 1990).

A Figura 3 apresenta os mapas dos padrões de vegetação do Banhado Grande. De acordo com a interpretação de Accordi \& Hartz (2006), os setores do banhado onde a vegetação se caracteriza pelo banhado alto pode ser interpretado como sendo constituídos por herbáceas, caracterizado por gramíneas altas, de até 2,5 metros de altura.

As espécies do gênero vegetação paludosa (Figuras 4, 5 e 6) são espécies de porte médio a relativamente alto (Erianthus sp., Andropogon bicornis e Sida sp.) e baixo (capim-boiadeiro e aguapés) e ocorre em porções centrais na maioria dos setores do Banhado (Figu- 

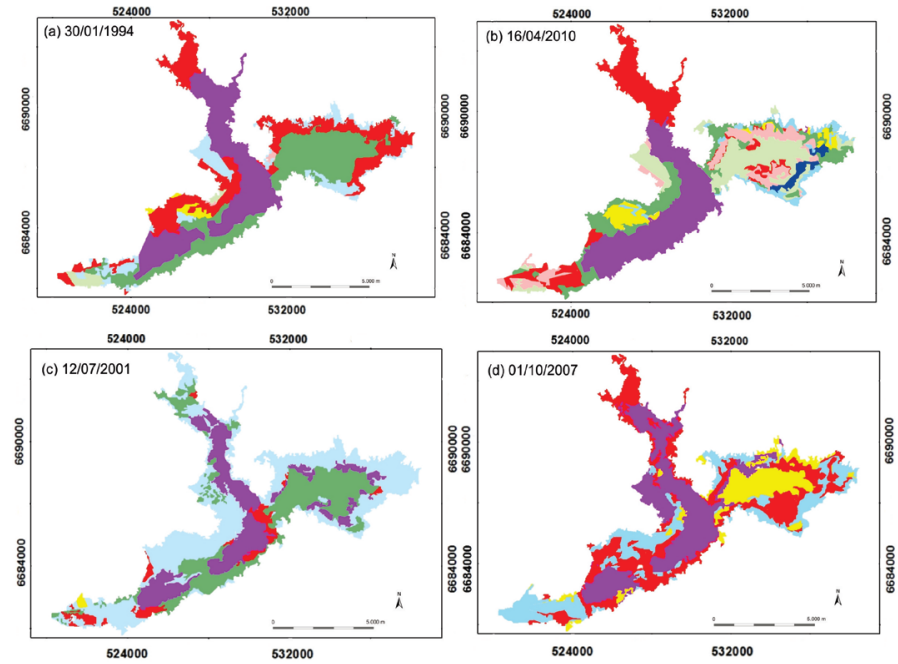

Legenda
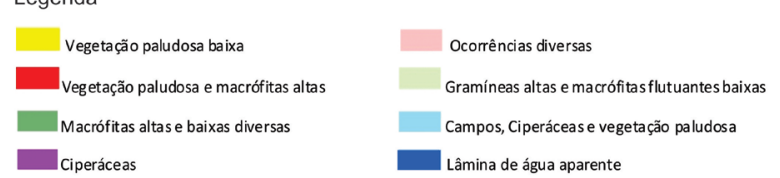

为娄

Macrófitas altas e baixas diversas

Figura 3. Padrões espaço-temporais de vegetação de macrófitas aquáticas no Banhado Grande, bacia hidrográfica do rio Gravataí, RS.

ra 3a) e principalmente na porção central.

Na Figura 4, observa-se a vegetação de ciperáceas e herbáceas de grande porte e na Figura 5, observa-se a vegetação paludosa de porte médio a relativamente alto (Erianthus sp., Andropogon bicornis e Sida sp.) e baixo (capim-boiadeiro e aguapés). Já as classes referentes às gramíneas e campos úmidos, por sua vez, concentram-se, predominantemente, nas bordas do Banhado.

Em algumas áreas ocorre uma grande mistura de gêneros e características vegetais, com a presença de macrófitas altas e baixas diversas (Figura 3). Essa característica pode sugerir uma área de transição, e explica porque este padrão vegetal se localiza predominantemente nas zonas de borda do banhado.

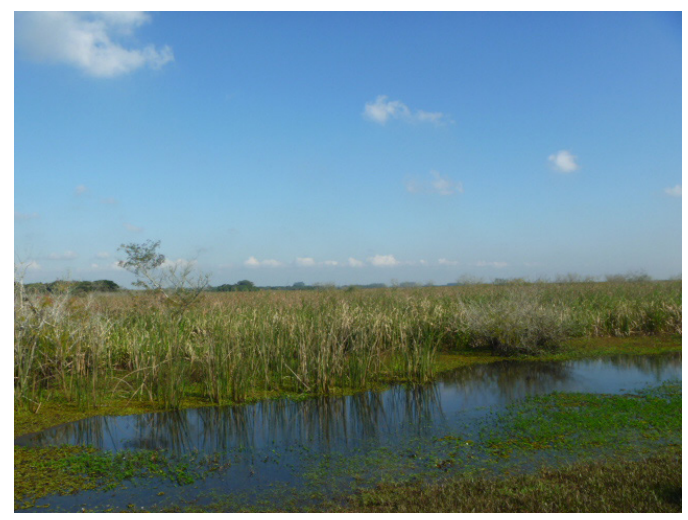

Figura 4. Campos Úmidos de borda e vegetação do "Banhado Alto" na parte superior da fotografia.

Com os estudos de Mello (1990; 1998), as imagens de satélite e a verificação de campo, constatou-se a presença marcante de rizicultura em grande parte do entorno do Banhado Grande. Segundo Biudes \& Camargo (2008), a presença da cultura do arroz e dos insumos

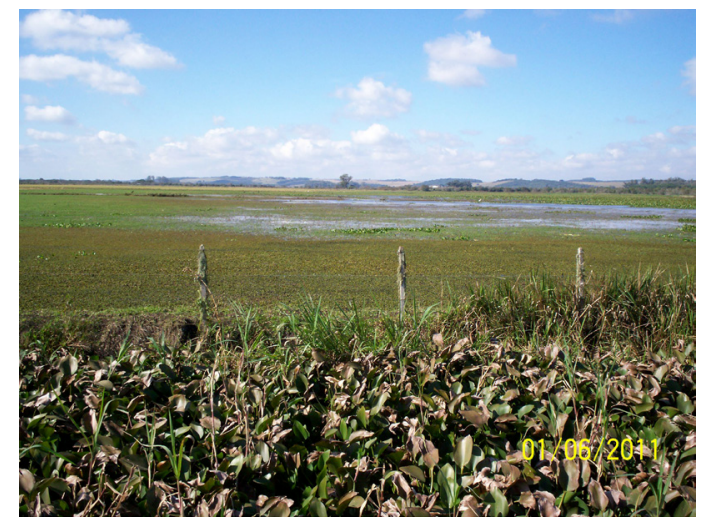

Figura 5. Espécies do "Banhado Baixo", na parte superior da fotografia.

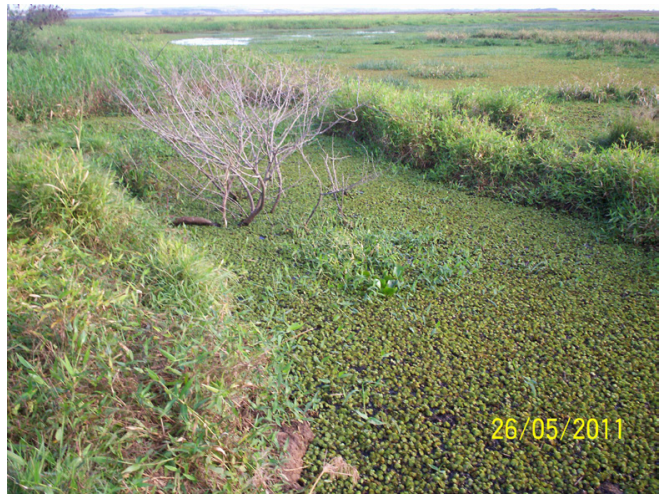

Figura 6. Gêneros de vegetação paludosa e campos úmidos na borda do Banhado Grande, RS.

mos agrícolas utilizados para a contribuição do processo de produção primária do arroz pode interferir, significativamente, na presença e até na diversidade dos padrões mistos de macrófitas aquáticas que se localizam nos setores de borda de áreas úmidas (Figuras 4 e 5).

$\mathrm{Na}$ imagem de outono, 16/04/2010 (Figura 3b), ocorre a supressão da classe de Ciperáceas. Nesse período não ocorre padrão semelhante entre as respostas espectrais da vegetação relacionada à água, e a dinâmica verificada nas imagens dificulta a análise dos padrões de distribuição, que pode estar relacionada com a própria dinâmica pluvial atuante na região (DNOS, 1985; UFRGS, 2002). A classe com maior abrangência espacial nessa imagem, Figura $3 b$, é vegetação paludosa, vegetação de porte médio e relativamente alto (Erianthus sp., Andropogon bicornis e Sida sp.) a baixo (capim-boiadeiro e aguapés).

Frantz et al. (1990) classificam em seu estudo a vegetação paludosa e a mistura entre a vegetação paludosa e as gramíneas (Figuras 3b e 7), como predominante em todas as áreas de banhado. Observa-se, na Figura 3, que a área a nordeste é o principal setor em que ela predomina em todas as estações do ano, em função, provavelmente, da hidrodinâmica daquele setor. Essa área é mais influenciada pela entrada de água do rio Gravataí, uma vez que os locais onde predomina a vegetação paludosa são aqueles com constante presença de lâmina d'água corrente (CARVALHO \& OZORIO, 2007).

Na Figura 3b, mapa da imagem de outono, ocorre a predominância de ciperáceas, e as coberturas vege- 
tais de borda, com presença de gramíneas altas na área interna da borda e campos úmidos nas regiões de borda mais distantes do centro do Banhado. Isso se deve, provavelmente, a lâmina de água aparente menos pronunciada do que as imagens de inverno e primavera, Figuras 2(c), 2(d), 3(c) e 3(d), o que denota uma paisagem relacionada a períodos de estiagem aparente. De forma secundária, predominam as espécies de grande e médio porte, fixadas ao solo ou fixadas aos chamados "solos flutuantes".

Os campos úmidos ocorrem predominantemente na borda e as gramíneas e macrófitas baixas flutuantes em direção à porção central do banhado. As Figuras 6 e 7 mostram fotografias de campo úmido em um dos setores de borda do Banhado Grande. Nota-se uma semelhança com os padrões de cobertura de lavouras de arroz, que ocorrem ao lado dos campos úmidos.

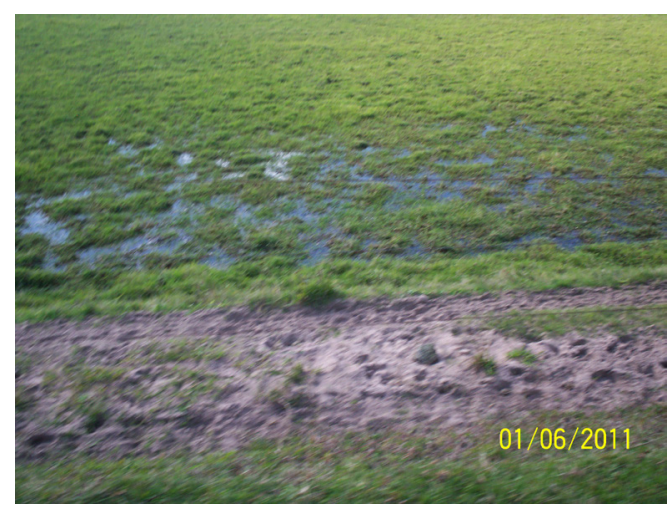

Figura 7. Campos úmidos seguidos por lavouras de arroz, na borda do Banhado Grande, RS.

No setor central do Banhado, a predominância de ciperáceas ocorre em todas as datas de imagens, o que denota um padrão na hidrodinâmica do Banhado.

A precipitação altera a circulação de água em toda a bacia (MELLO, 1990). Por consequência, o Banhado Grande, que funciona como regulador das vazões do rio Gravataí (DNOS, 1985; MELLO, 1990 e 1998; UFRGS, 2002), também sofre alterações no regime de sua circulação de água em função da quantidade de água que recebe por precipitação, o que afeta a dinâmica de inundações no Banhado.

De acordo com Ferreira (2005), o verão e o inverno são as épocas normais de ocorrência de maior senescência das macrófitas aquáticas. 0 outono e a primavera são as épocas normais da ocorrência de uma maior produção primária das macrófitas aquáticas. Isso indica que, a menor presença de lâmina d'água aparente nas imagens de outono com relação às de inverno e da primavera, provavelmente estão relacionadas a um papel mais pronunciado da cobertura vegetal de macrófitas, principalmente as de grande porte, como as ciperáceas do setor central do Banhado Grande, e não de menor presença real de água. Ademais, o setor central do Banhado, em todas as imagens orbitais, mostra que não há presença de lâmina de água aparente neste setor.

Na imagem de inverno,12/07/2001 (Figura 3c), constata-se uma presença maior da lâmina d'água aparente com relação às imagens de verão e outono. Isso, possivelmente, está relacionado com outra característica marcante das imagens de inverno, mas ligada às respostas espectrais da vegetação, que é o fato destas imagens apresentarem um número menor de classes com relação às imagens de outras estações, principalmente às de verão e primavera.

Essa diminuição da presença de classes nos mapas está relacionada, possivelmente, com a temperatura, significativamente menor no inverno do que no verão na área segundo UFRGS (2002). Biudes \& Camargo (2008), observaram que a temperatura afeta na produção primária e na diversidade sazonal de macrófitas aquáticas no Pantanal mato-grossense. Descrevem que à medida que aumenta a temperatura e quantidade de luz, a produção primária foi ligeiramente menor para a maioria das espécies estudadas.

$\mathrm{Na}$ imagem de inverno, a classe de cobertura vegetal que mistura gêneros de ciperáceas, de vegetação paludosa, de gramíneas e de campos úmidos, tem grande área de abrangência. Essa classe apresenta também uma significativa área de abrangência espacial, principalmente nos setores de borda em praticamente toda a extensão do Banhado Grande.

0 domínio de cada gênero está relacionado ao setor do banhado onde ocorre. A vegetação paludosa predomina no setor nordeste, as gramíneas e os campos úmidos predominam nas bordas. A região nordeste apresenta uma nítida predominância do padrão de cobertura vegetal de macrófitas altas alternadas com ciperáceas de médio e grande porte (Figura 9).

A imagem de primavera, de 01/10/2007 (Figura $3 \mathrm{~d}$ ), apresenta maior umidade aparente dentre as imagens selecionadas. Há a predominância do padrão de ciperáceas no setor oeste do Banhado, e de vegetação paludosa baixa no setor nordeste, onde predominam os gêneros Polygonum sp. e Leersia sp.. Esse padrão apresenta maior área de abrangência espacial do que as imagens de verão, outono e inverno, quando aparentemente inexistente. Nesta imagem, nas bordas do Banhado predomina a ocorrência das ciperáceas, gramíneas e campos úmidos.

Nas imagens de outono e inverno, contudo, as áreas de bordas aparecem com uma área reduzida, com presença de vegetação paludosa de pequeno a médio porte. Nas imagens de verão e outono, essa classe se mostrava predominante nos setores central, norte e sul. As variações espaciais dos padrões na imagem de primavera com relação às de outono e inverno estão diretamente ligadas à variação da precipitação. Nesse período não há retirada de água para o cultivo de arroz nas áreas adjacentes ao Banhado (MELLO, 1990), com pouco aporte de nutrientes para o Banhado, que poderia auxiliar em um eventual aumento da produção primária de macrófitas (BIUDES \& CAMARGO, 2008). 
DNOS (1985); Mello (1990); UFRGS (2002) apontam para a primavera como o período de maior precipitação na região da bacia do rio Gravataí, o que se relaciona com a presença de maior lâmina de água aparente na imagem desta estação com relação às imagens das demais estações, associado aos pulsos de inundação na região.

A lâmina d'água mapeada nas imagens considerou apenas a lâmina d'água livre, sem a presença de vegetação o que, todavia, não exclui a presença de grande umidade aparente na imagem orbital de primavera. As áreas com maior influência da lâmina d'água, mas que apresentavam presença de vegetação misturada se mostraram mais difíceis para o mapeamento.

Conforme Málvarez (1997), os pulsos inundação ocorrem em um padrão que oscila de forma sequenciada, quando ocorrem períodos de estiagem e em períodos de cheias. Tal caráter oscilatório caracteriza um ciclo, ou seja, um padrão de pulsos de inundações alternando-se sazonalmente (IBAMA, 2000). No Banhado Grande, na primavera, portanto, os pulsos de inundação apontam para um período de cheia, que aumenta a circulação de água no Banhado (DNOS, 1985). 0 aumento da circulação de água é possivelmente causa direta do padrão de distribuição espacial da vegetação paludosa. Como na primavera ocorrem as maiores precipitações, nesse período o maior aporte de água para os cursos d'água que fornecem água para o Banhado Grande, e o aumento dos pulsos de inundação, tem prováveis relações com as modificações espaço-temporais dos padrões de vegetação na imagem de primavera.

A partir da quantificação da área referente às classes de vegetação, Quadro 2, constata-se, que a dinâmica da vegetação do Banhado Grande possui um padrão de variação sazonal apenas parcial, apesar de que em todas as estações do ano nota-se uma variação da área dos padrões de vegetação de macrófitas aquáticas. Os padrões com diferenças mais pronunciadas são os de vegetação paludosa de macrófitas flutuantes, devido a sua maior mobilidade, são mais suscetíveis à ação dos ventos e da dinâmica de circulação da água (ARBO et al., 2001), do que as macrófitas de médio e grande porte, fixadas ao solo.

\section{CONSIDERAÇÕES FINAIS}

A análise da série temporal de imagens de satélite, entre 1994 e 2010, permitiu analisar a variabilidade e os padrões da dinâmica da vegetação no Banhado Grande.

Constatou-se, que essas variações espaço-temporais na dinâmica da vegetação e na variabilidade hidrodinâmica ocorrem de acordo com um padrão de distribuição sazonal. Entretanto, essa sazonalidade é parcial, principalmente considerando o verão e o inverno, enquanto que no outono e na primavera há uma variabi

\section{lidade maior.}

As bordas do banhado mostram predominância de uma mistura de ciperáceas, gramíneas, vegetação paludosa e campos úmidos, na primavera. No outono e no inverno, entretanto, há pequena variação de vegetação nas bordas, com predomínio de vegetação paludosa de médio a pequeno porte. No setor central, norte, sul e sudeste, predominam a vegetação de ciperáceas, no verão e outono.

Essas diferenças espaciais dos padrões na primavera, outono e inverno estão, provavelmente, relacionadas à variação da precipitação. Apesar dos significativos índices de precipitação no verão, a vegetação recobre a lâmina de água aparente no Banhado, tornando-a, praticamente imperceptível nesse período.

\section{SPACE-TIME DYNAMICS OF AQUATIC MACROPHYTES IN BANHADO GRANDE, GRAVATAÍ RIVER BASIN, RS.}

Abstract - Marshes are one among several typifications of wetlands. Its importance is linked to the flow control function of surface wtarer bodies which are associated as well as habitat for different species. The understanding of the dy-

Quadro 2. Área (km2) das classes de vegetação do Banhado Grande, bacia do rio Gravataí, RS.

\begin{tabular}{|l|c|c|c|c|}
\hline \multicolumn{1}{|c|}{ CLASSES } & \multicolumn{2}{|c|}{ Área (km2) das classes de vegetação } \\
\cline { 2 - 5 } & $\begin{array}{c}\text { verão } \\
30 / 01 / 1994\end{array}$ & $\begin{array}{c}\text { outono } \\
16 / 04 / 2010\end{array}$ & $\begin{array}{c}\text { inverno } \\
12 / 07 / 2001\end{array}$ & $\begin{array}{c}\text { primavera } \\
01 / 10 / 2007\end{array}$ \\
\hline $\begin{array}{l}\text { Predominância de vegetação paludosa baixa (capim-boiadeiro: Polygnum sp. } \\
\text { e Leersia sp.) }\end{array}$ & 0,77 & 2,18 & 0,24 & 3,68 \\
\hline $\begin{array}{l}\text { Predominância de vegeração paludosa (capim-boiadeiro e aguapés) } \\
\text { e Gramíneas altas (Erianthus sp., Andropongon bicornis e Sida sp.) }\end{array}$ & 16,09 & 10,56 & 3,45 & 18,54 \\
\hline $\begin{array}{l}\text { Predominância de vegetação de macrófitas altas e baixas diversas } \\
\text { (transição e bordas) }\end{array}$ & 16,78 & 9,22 & 15,74 & 0,00 \\
\hline $\begin{array}{l}\text { Predominância de Ciperáceas - Tiriricas, Juncos e Sarandis } \\
\text { (Fuirena robusta, Cyperus sp., Scirpus sp. e Cephalanthus sp.) }\end{array}$ & 16,82 & 16,63 & 13,07 & 18,78 \\
\hline Ocorrências diversas (presença de Ciperáceas) & 0,24 & 6,60 & 0,00 & 0,00 \\
\hline $\begin{array}{l}\text { Predominância de Gramíneas altas } \\
\text { e macrófitas flutuantes baixas (bordas) }\end{array}$ & 1,17 & 10,56 & 0,00 & 0,00 \\
\hline Campos úmidos. Vegetação Paludosa. Gramíneas Altas e Ciperáceas & 6,77 & 4,53 & 27,76 & 14,42 \\
\hline Lâmina de água aparente & 0,00 & 0,74 & 0,00 & 0,00 \\
\hline
\end{tabular}


namics of wetlands suggests a spatio-temporal approach in order to measure and describe the key elements of the landscape and understand its operation. This study investigates the temporal dynamics of the spatial distribution of aquatic macrophytes in Banhado Grande, Gravataí river basin, RS, with the use of remote sensing and GIS. Maps were related to different patterns of spatial-temporal distribution of vegetation from LANDSAT-TM satellite images, in the period between 1994 and 2010, grouped by seasons. The spatio-temporal variations observed in this study are associated with the variability of the hydrodynamic of the system. However, this pattern is only partly seasonal.

Keywords - Banhado Grande. Gravataí river basin. Spatial-temporal dynamics. Aquatic macrophytes. Remote sensing.

\section{REFERÊNCIAS}

ACCORDI, I. (2003) 0 Complexo Banhado Grande como uma área de importância internacional. In: The RAMSAR Convention on Wetlands. Ramsar, Irã. Disponível em <http://www.ramsar.org/index.html>. Acesso em: 8 nov. 2011. P. $156-165$.

ACCORDI, I.; HARTZ, S. M. (2006) Distribuição espacial e sazonal da avifauna em uma área úmida costeira do sul do Brasil. In: Revista brasileira de Ornitologia, p. 117-135.

ARBO, M.M.; LÓPES, M.G.; SCHININI, A.; PIESZKO, G. (2001) Plantas palustres del macrossistema Iberá. Instituto de Botânica del Nordeste (IBONE). 4 p.

BIUDES, J.F.V.; CAMARGO, A. F. M. (2008) Estudo dos fatores limitantes à produção primária por macrófitas aquáticas no Brasil. Oecol. Bras., 12 (1): 7-19, 2008.

BULHÕES, F.M.; GIUGNO, N.B. (1994). Cobertura vegetal e ocupação atual do solo da área de influência da Barragem Olaria Velha e da Bacia do rio Gravataí RS. Porto Alegre: CPRM/METROPLAN. 1 v. não paginado, il. (Série Ordenamento Territoral, 2).

CARVALHO, A.B.P.; OZORIO, C.P. (2007) Avaliação sobre os banhados do Rio Grande do Sul, Brasil. In: Revista de Ciências Ambientais, Canoas: v. 1, n², p. 83 a 95.

COMPANHIA DE PESQUISAS EM RECURSOS MINERAIS CPRM - Disponível em Homepage: <http://www.cprm. gov.br/>. Acesso em: 14 ago. 2011.

DEPARTAMENTO NACIONAL DE OBRAS E SANEAMENTO (DNOS). (1985). Planejamento Integrado dos Recursos Hídricos da Bacia do rio Gravataí. Projeto de coordenação técnica Brasil-Alemanha. Estudos integrados de bacias hidrográficas, v.1.142p.

ECOPLAN ENGENHARIA; COMPANHIA RIO-GRANDENSE DE SANEAMENTO (CORSAN). (1992). Barragem Olaria Velha - Rio Gravataí. Porto Alegre. v. 1.72 p.

FRANTZ, D.L.S.; CARRARO, C.C.; VERDUM, R.; GARCIA, M.A.T. (1990) Caracterização de ambientes paludais da Planície Costeira do Rio Grande do Sul em Imagens Orbitais TM/LANDSAT 5. Centro Estadual de Pesquisas em Sensoriamento Remoto e Meteorologia. P. 408-418.

FUNDAÇÃO ZOOBOTÂNICA DO RIO GRANDE DO SUL. Museu de Ciências Naturais. (1983). Amostragem da flora e fauna das nascentes do rio Gravataí, Rio Grande do Sul, visando a emissão de um parecer sobre as condições bióticas da área nos meses de março, abril e maio de 1983. Relatório Final. Porto Alegre. P.1-6.

GUASSELLI, L.A. (2005) Dinâmica da Vegetação no Banhado do Taim, RS. Programa de Pós-Graduação em Recursos Hídricos e Saneamento Ambiental/UFRGS. Tese de Doutorado. 157 p.

INSTITUTO BRASILEIRO DO MEIO AMBIENTE E RECURSOS NATURAIS RENOVÁVEIS. (2000). Banhados. Disponível em: <http//www.ibama.gov.br.> Acesso em: 17 ago. 2010.

IRGANG, B.E.; GASTAL Jr., C.V.S. (1996) Macrófitas aquáticas da planície costeira do Rio Grande do Sul. Porto Alegre: Edição dos autores, 290p.

JUNK, W. J. (1997) The Central Amazon floodplain. Vol. 1, No1, 1997, Berlin: Springer, 525 p.

LEIBOWITZ, S.G. (2003) Isolated Wetlands and their functions: an ecological perspective. WETLANDS, Vol. 23, No. 3, September 2003, pp. 517-53.

LEITE, M.G. (2011) Dinâmica espaço-temporal da vegetação no Banhado Grande, Bacia hidrográfica do rio Gravataí, RS. Porto Alegre, RS. Universidade Federal do Rio Grande do Sul, Instituto de Geociências. Trabalho de Conclusão de Curso/Bacharelado em Geografia. 96p.

MALVAREZ, A.I., (1997). Las comunidades vegetales del Delta del Río Paraná. Su relación com factores ambientales y patrones del paisaje. Tesis doctoral, UBA, Buenos Aires, 167 p.

MELLO, L.P. (1990) Barragem da Olaria Velha, rio Gravataí: contribuições para uma avaliação de impacto ambiental. Departamento de Geografia, Especialização em Geografia Ambiental Urbana. Instituto de Geociências, UFRGS, Porto Alegre, Rio Grande do Sul. P. 9 - 38.

MELLO, L.P. (1998) Percepção da paisagem e conservação ambiental no Banhado Grande do Rio Gravataí (RS). Tese de Doutorado. Universidade de São Paulo, São Paulo. 364p.

MENEGHETI, J.O.; (1998). Lagunas uruguayas y sur de Brasil. In: CAVENARI, P.; DAVIDSON, I.; BLANCO, D.; CASTRO, G.; BUCHER, E. (eds). Los humedales de America del Sur, uma agienda para la conservación de La biodiversidad y politicas de desarollo. Buenos Aires: Wetlands International.

NEIFF, J.J. (1997) El regimén de pulsos en rios y grandes humedales de Sudamérica. En: Tópicos sobre grandes humedales sudamericanos, Málvarez, A. I. y P. Kandus (eds.), 1997. ORCYT-MAB (UNESCO). Motevideo, Uruguay, $106 \mathrm{p}$. 
NEIFF, J.J., IRIONDO, M. H. \& CARIGNAN, R. (1994) Large tropical South American wetlands: an overview. In: LINK, G. L.; NAVAN, R.J. The ecology and management of aquatic-terrestrial ecotones. Proceedings book. University of Washington. Notas Técnicas: CECO/UFRGS, Porto Alegre, v. 8, n. 1, p. 1-45.

NOVO, E.M.L.M. (2008) Sensoriamento Remoto: princípios e aplicações. São Paulo: Edgard Blucher. P. 261-274.

RAMSAR (1999) The Ramsar library. Information sheet on Ramsar wetlands. Gland: the Ramsar Convention
Bureau.

TOMAZELLI, L.J.; VILLWOCK, J.A. (2000). 0 Cenozóico no Rio Grande do Sul: Geologia da Planície Costeira. In: HOLZ, M.; DE ROS, L. F. (Ed.). Geologia do Rio Grande do Sul. Porto Alegre: CIGO/UFRGS. p. 375- 406.

UNIVERSIDADE FEDERAL DO RIO GRANDE DO SUL (2002) Instituto de Pesquisas Hidráulicas. Identificação das alternativas possíveis e prováveis para regularização das vazões do rio Gravataí. Porto Alegre: CPRM. P. 1-8. 